\title{
Failure cue priming and impaired cognitive performance-analyses of avoidance motivation as a mediator and fear of failure as a moderator
}

\author{
JULIA SCHÜLER ${ }^{1 *}$, VERONIKA BRANDSTÄTTER ${ }^{2}$ AND NICOLA BAUMANN ${ }^{3}$ \\ ${ }^{1}$ University of Bern, Bern, Switzerland; ${ }^{2}$ University of Zurich, Zurich, Switzerland; ${ }^{3}$ Department of Psychology, \\ University of Trier, Trier, Germany
}

Abstract

The present research investigates whether and how learned symbols for failure reduce task performance. We tested the effect of number priming in two countries with different learning histories for numbers. Priming numbers associated with failure (6 in Germany and 1 in Switzerland) were hypothesized to reduce performance. As expected, in Switzerland, priming with the failure number 1 reduced performance (Study 1), whereas in Germany, priming with the failure number 6 impaired performance in analogy tasks (Study 2). Study 2 additionally analyzed the mechanism and showed that the relationship between failure number priming and performance was mediated by evoked avoidance motivation and that dispositional fear of failure moderated this mediation.

A large body of research convincingly shows that avoidance motivation impairs performance and well-being (Coats, Janoff Bulman, \& Alpert, 1996; Elliot, 2008). However, far less is known about the specific triggers of avoidance motivation. The present research suggests that arbitrarily chosen cues can become learned symbols for negative incidence to be avoided (e.g., failure) and thus evoke avoidance motivation, which in turn reduces performance in cognitive tasks. In addition to this mediation assumption which is deduced from the findings of previous research (see below), we suggested that a person factor, which is fear of failure, intensifies the effect of failure cues on motivation and performance.

In a variety of achievement contexts, figurative symbols (e.g., thumbs up and thumbs down in sports) symbolize success and failure, and numbers are also used to evaluate performance. Particularly, in school contexts, numbers are used in the form of grades as measures of excellence to evaluate the level of achievement. In Switzerland and Germany, a six-point grading scale (numbers from 1 to 6 ) is used to evaluate students' performance, whereby the two countries differ with respect to the meaning of the numbers. The best grade stands for "excellent" and is given for outstanding performance (6 in Switzerland and 1 in Germany), followed by "good," "satisfactory," "sufficient," and "deficient." The lowest grade (1 in Switzerland and 6 in Germany) stands for "insufficient" and is given when students fail to meet the classroom standards and have not understood the basic subject matter. Teachers start to use these highly evaluative grades in about the third grade of primary school, when the students are 8 or 9 years old. The present research argues that this grading practice results in a strong learned association between specific numbers and a sense of failure.
Because failure is clearly associated with avoidance tendencies (Atkinson, 1957), it is feasible to assume that numbers representing failure might instigate the corresponding avoidant behavioral tendency. Based on previous research on automatic priming effects (Bargh \& Chartrand, 1999; Ciani \& Sheldon, 2010; Elliot, Maier, Moller, Friedman, \& Meinhardt, 2007; Elliot, Maier, Binser, Friedman, \& Pekrun, 2009), we assumed that symbols of failure, such as grades, may function as primes that automatically activate avoidance motivation. Furthermore, we drew on research demonstrating that avoidance motivation has negative effects on performance (e.g., Elliot \& McGregor, 1999). Putting together the assumptions mentioned earlier, we hypothesized that the numbers 1 (in Switzerland) and 6 (in Germany) should automatically evoke avoidance motivation without participants being aware of this and thereby impair their performance. This effect is assumed to occur outside the conscious awareness of the individual.

A further important extension of our model has its roots in research on the achievement motive (e.g., McClelland, 1985; McClelland, Atkinson, Clark, \& Lowell, 1953). We assumed that the mediation described earlier is first of all true for individuals who are particularly sensitive towards signals of failure (i.e., individuals with a high fear of failure).

\section{THE AUTOMATIC PRIMING OF MOTIVATION AND ITS EFFECTS}

A great variety of mental processes and behaviors unfold without an individual's conscious intention (Bargh \& Chartrand, 1999). 
Subtle environmental cues such as lexical and contextual stimuli (Aarts \& Dijksterhuis, 2003) may prime processes such as motivation, stereotypes, and behavior implicitly (DeMarree, Wheeler, \& Petty, 2005; for a review, see Bargh \& Chartrand, 1999). Also, avoidance tendencies have been shown to be automatically evoked by subtle cues (Bargh \& Chartrand, 1999; Cacioppo, Gardner, \& Berntson, 1999). The underlying process is assumed to be that individuals automatically classify incoming stimuli as to whether they are unpleasant or pleasant, which in turn results in immediate avoidance and approach tendencies (Bargh \& Chartrand, 1999).

Evoked avoidance and approach tendencies find their expression in concrete actions such as muscular movements (Chen \& Bargh, 1999; Elliot et al., 2009; Puca, Rinkenauer, $\&$ Breidenstein, 2006). Other researchers have analyzed the effects of priming on behavioral indicators (e.g., choice of an easy rather than a moderately difficult task, Elliot et al., 2007), cognitive indicators (e.g., lower number of achievement words in a word-stem completion task, Ciani \& Sheldon, 2010), and psychophysiological indicators of avoidance tendencies (right, relative to left, and frontal cortical activation, Elliot et al., 2007). In summary, previous research demonstrates that avoidance motivation can be primed without people being aware of it.

Avoidance motivation has fundamental consequences for a variety of outcome variables. Thus, it impairs well-being (Coats et al., 1996; Elliot \& Sheldon, 1997) and motivation (Elliot \& Church, 1997). Avoidance motivation also impairs performance in complex cognitive tasks (Elliot \& Church, 1997; Elliot \& McGregor, 1999, 2001; Elliot \& Friedman, 2007; Elliot \& Thrash, 2001; Elliot et al., 2007). The underlying mechanism is that avoidance motivation increases cognitive and physiological arousal, such as fear and test anxiety, and self-protective processes, which in turn diminish performance (Birney, Burdick, \& Teevan, 1969; for a review, see Elliot, 2005). To summarize, previous research suggests that avoidance motivation has negative effects on performance in achievement contexts such as educational settings.

A few studies in academic learning settings have already indicated that the effects of environmental cues on performance might be mediated by avoidance tendencies. For example, one line of research tested the effect of the color red on avoidance tendencies and performance in achievement contexts (Elliot \& Maier, 2007; Elliot et al., 2007, 2009; Maier, Elliot, \& Lichtenfeld, 2008). The authors assume that the color red due to learning processes (mistakes are marked with red) and a biological predisposition (red as a signal of danger) operates as a prime, which automatically evokes an avoidance tendency or impairs cognitive performance (Elliot et al., 2007). The authors confirmed their assumption that avoidance motivation impaired performance in different cognitive tasks (anagram tasks and numeric subtests of intelligence test; e.g., Elliot et al., 2007). Maier et al. (2008) tested the whole underlying mechanism between failure color priming and performance and revealed evoked avoidance motivation as a mediator. Interestingly, the color green, which was assumed to carry the antagonistic approach-oriented meaning of "go" (e.g., Elliot et al., 2007), was indeed found to be associated with success words (Moller, Elliot, \& Maier, 2009). However, priming with "green" did not enhance performance (Elliot et al., 2007).
Ciani and Sheldon (2010) used letter primes and found that $\mathrm{F}$ (grade indicating having failed an exam) decreased motivation and performance compared with A (grade indicating having passed an exam) on approach and avoidance motivation and performance. Compared with a control group (letter J), participants in the letter $\mathrm{F}$ condition performed worse. The performance-enhancing effect of the letter A was weaker, again indicating that the effects of failure primes were stronger than the success prime effects.

Because the previous research mentioned earlier has revealed inconsistent results regarding the effect of success cues, with the majority of studies showing that symbols carrying approach-oriented meaning do not enhance performance (e.g., Elliot et al., 2007, Studies 1 to 6; Ciani \& Sheldon, 2010, Study 2) (for an exception, see Ciani \& Sheldon, 2010, Study 3), the present research explored the effects of approach cues without formulating a hypothesis.

\section{PRESENT RESEARCH}

Previous research left two important questions open. The first one is why environmental cues carry the meaning of failure. Elliot et al. (2007) assumed that the color red is associated with the danger of failure due to learning processes as well as a biologically based predisposition to perceive red as a signal for danger. In contrast, the results presented by Ciani and Sheldon (2010) indicate that the association between the letters $\mathrm{A}$ and $\mathrm{F}$ and performance evaluation is based on learning processes. The second question is about the supposed general validity of the prime avoidance motivation performance mediation. Is the assumed mediation effect indeed general or influenced by individual differences in the sensitivity for failure cues (e.g., fear of failure)?

The present research aimed to answer these questions. First, we intended to provide stronger evidence that learning processes are a sufficient condition for the link between cues and the success and failure meaning. As an extension to Ciani \& Sheldon's (2010) studies in which only one learned failure cue was tested among individuals with the same learning history regarding this cue, we aimed to demonstrate that the same cue has the opposite effect on motivation and performance depending on different learning histories. Therefore, in the present studies, we tested samples for which numbers have exactly the opposite meaning: in Switzerland, " 6 " is the best grade and "1" the worst grade. Conversely, in German academic settings, the grade " 1 " indicates the best and the grade " 6 " the poorest performance. We hypothesized that in our Swiss sample (Study 1), the number "1" would impair performance compared with the number "6" and compared with a control number by evoking a high avoidance motivation. The effect was expected to be reversed in the German sample (Study 2). No hypotheses were formulated for the performance-enhancing effects of success primes (compared with control primes).

Our second aim was to analyze the process which underlies the failure prime and impaired performance relationship in more detail. We aimed to strengthen the assumption that the meaning of failure does indeed evoke avoidance motivation. 
A convincing argument would be to show that individuals who are known to be chronically avoidance-motivated react more strongly (regarding evoked avoidance motivation and their consequences) to symbols of failure than individuals who are less chronically avoidance-motivated. According to motivation psychology, this is true for individuals with a high versus low fear-of-failure motive (McClelland, 1985). Research and theorizing on implicit motives (e.g., McClelland et al., 1953; Brunstein \& Heckhausen, 2008) show that achievement settings such as academic exams and evaluation of performance have different effects on performance, intrinsic motivation and emotion depending on the individual's achievement motive, especially depending on the avoidance-motivated component of the achievement motive, that is fear of failure (McClelland, 1985; McClelland et al., 1953).

Trying to avoid the negative emotional consequences associated with failure, individuals with a high fear of failure are highly sensitive towards environmental cues that signalize the evaluation of their competence (McClelland et al., 1953). However, because the anticipation of failure increases avoidance motivation and test anxiety, and decreases optimism and self-efficacy expectations, the task performance of individuals with a high fear of failure is impaired (e.g., Covington \& Omelich, 1991). Referring to this line of research, we hypothesized and tested in Study 2 that individuals with high fear of failure will react more strongly to primes that are associated with failure in achievement settings (e.g., grades) than individuals with low fear of failure. The stronger reaction includes higher avoidance motivation and, mediated by this, also impaired cognitive performance.

We additionally assessed participant's hope for success which is the approach-oriented component of the achievement motive (McClelland, 1985; McClelland et al., 1953). Although hope-for-success-motivated individuals are theoretically not particularly sensitive towards cues signaling failure, they are nevertheless generally sensitive towards achievement cues and the evaluation of their performance and thus might also be affected by the failure primes. No hypotheses were formulated for the hope of success motive.

In a nutshell, our research contributes to previous findings by testing fear of failure as a moderator of a failure prime avoidance motivation impaired performance mediation.

The present research comprises two experimental studies that address different aspects of the hypotheses described earlier. In the first study, we analyzed a sample of Swiss undergraduate students whether numbers (grades 1 and 6) function as primes, which have an impact on performance. Study 2 used a German sample and hence the German grading system, which is opposite to that in Switzerland. In Study 2, we additionally assessed avoidance motivation and tested the mediation hypothesis that failure-priming numbers influence performance through evoked avoidance motivation. Furthermore, we tested whether fear of failure moderates the effect of priming on avoidance motivation and performance.

\section{STUDY 1}

We hypothesized that participants who were assigned to the failure priming number 1 group would perform worse than participants in the success priming number 6 group and the control number 7 group, which was expected to lie in between the two groups. No hypothesis was formulated regarding whether the success priming number 6 group would perform better than the control group. Task performance was operationalized by performance in an analogy task.

\section{Participants and Procedure}

Sixty-two Swiss undergraduate students (51 women) with a mean age of 26.5 years $(S D=5.96)$ participated in the study. They were tested as a group at the beginning of an introductory course in the psychology of emotion and were told that the study was aimed at developing different parallel versions of an intelligence test. After a brief verbal introduction and the presentation of sample items, participants started with a practice test containing 20 items of an analogy task (T1, baseline measure). Five minutes later, they were asked to stop and were given a second test booklet containing another 20 analogy tasks, which were presented as the real test. The first page differed depending on the experimental group to which participants were randomly assigned. For participants in the failure priming number 1 group $(n=18)$, the cover page displayed a huge number 1 , allegedly indicating the version of the test. Participants in the success number 6 group $(n=22)$ and the control number 7 group $(n=22)$ received the alleged test versions 6 and 7, respectively. They were then asked to copy their test version number into the top righthand corner of all subsequent pages without looking at the test items. The alleged reason was that technical problems with the word processing program had prevented the test version number from being automatically copied and that the experimenter had to match up the materials (the sheets were not tacked) at a later point in time. Participants started to work on the second set of analogy tasks and after 5 minutes, the experimenter announced that the time had expired and instructed everyone to return the test booklet. In a last short questionnaire, we adapted items from Elliot et al. (2007) to measure participants' awareness of the number prime and suspicion ("What do you think we were trying to test in our study?," "Please guess what the purpose of the test version number might have been," and "Please name the test version number"). The questionnaire ended by thanking participants for taking part in the study. The data collection lasted about 20 minutes.

\section{Materials}

\section{Analogy Task Performance}

Performance was measured using the analogy subtest of the Intelligence Structure Test (Amthauer, Brocke, Liepmann, \& Beauducel, 1999). Here, two pairs of items were presented (e.g. expensive: rare) and participants had to complete the second pair of items (e.g., cheap : ?) choosing from five options (e.g. low-priced, stable, affordable, ordinary, and often; often is the correct answer). The correct number of analogy tasks served as the performance measure. One analogy test form with 20 items was used for the T1 baseline measure, and a 20-item parallel test form for the T2 performance measure. 
a) Performance in Swiss Sample

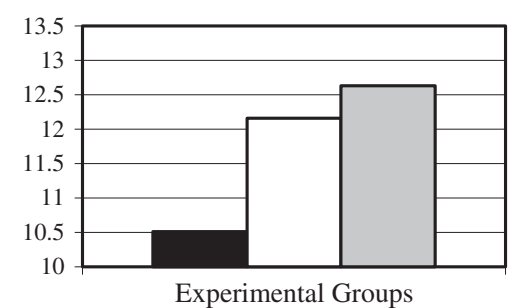

b) Performance in German Sample

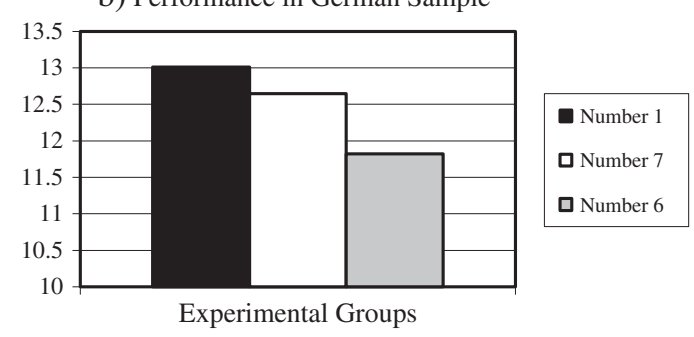

Figure 1. The effect of prime number on performance in analogy tasks in (a) a Swiss sample of undergraduate students (Study 1) and (b) a German sample of undergraduate students (Study 2)

\section{Results and Discussion}

\section{Awareness of Number}

The analysis of the short final questionnaire showed that all participants recalled the test version number correctly. Not a single participant guessed that the version number had anything to do with the experiment. All participants were unaware of the purpose of the experiment.

\section{Analogy Task Performance}

On average, participants solved 11.87 analogy tasks $(S D=2.20)$ at $\mathrm{T} 1$ and $11.86(S D=2.76)$ at $\mathrm{T} 2$. The performance measures were significantly correlated with each other $r=0.52(p<0.001$, $N=62$ ).

An analysis of covariance controlling for performance at $\mathrm{T} 1$ revealed a significant effect of prime type on performance at $\mathrm{T} 2, F(2,58)=4.46, p<0.05, \varepsilon^{2}=0.13$. Pairwise comparisons adjusted for multiple comparisons (Sidak) revealed that performance of the failure symbol group $(M=10.51, S E=0.54)$ differed significantly from the performance of the success symbol group $(M=12.63, S E=0.50)$, (mean difference $=-2.12$, $S E=0.74, p=0.02,95 \%$ CI: LL 3.94 to UL 0.30$)$ and marginal from the control group $(M=12.16, S E=0.47)$, (mean difference $=-1.65, S E=0.72, p=0.07,95 \% \mathrm{CI}$ : LL 3.41 to UL 0.12). However, the success symbol and the control group did not differ significantly (mean difference $=0.47, S E=0.69$, $p=0.87,95 \%$ CI: LL 1.22 to UL 2.17). The results are illustrated in Figure 1(a).

The study confirms our assumption that numbers are learned symbols of failure and success and therefore influence task performance. Although participants were able to report their test version number, they did not guess the purpose of the numbers or the aim of the study. This indicates that, as expected, number priming is a process that occurs outside people's awareness.

\section{STUDY 2}

In Study 2, we hypothesized that the relationship between the failure prime and reduced performance is mediated by evoked avoidance motivation. In addition, we hypothesized that the effect of priming a failure number through evoked avoidance motivation is moderated by fear of failure. The conceptual moderated mediation model is depicted in Figure 2. We

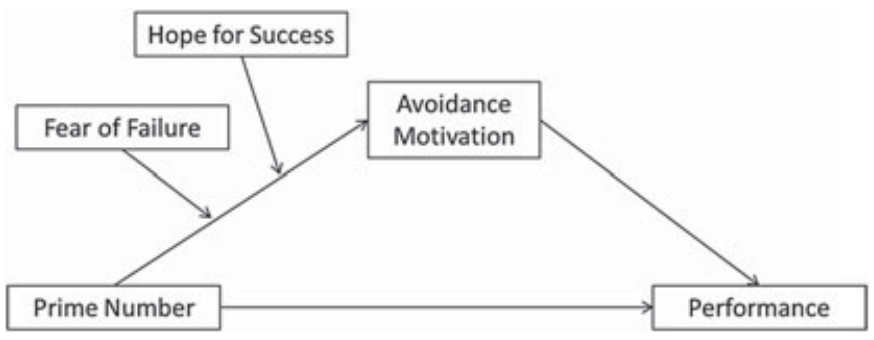

Figure 2. Conceptual model estimating the effects of prime number on performance in analogy tasks directly as well as indirectly through avoidance motivation, with indirect effects moderated by fear of failure and hope for success (Study 2)

expected the mediating effect of evoked avoidance motivation on performance to occur at moderate and/or high (but not at low) levels of fear of failure. This is because sensitivity to failure signals is likely to be exaggerated for those with fear of failure. Alternatively, when fear of failure is low, avoidance motivation may be more difficult to evoke and thus, is not likely to mediate performance. Because hope for success may increase the sensitivity for achievement cues and thus moderate the impact of priming a success number or may also influence the priming of a failure number, we included this additional factor in the analysis.

\section{Participants and Procedure}

One hundred psychology undergraduates (70 women, 29 men, and 1 missing value) from the University of Trier, Germany voluntarily participated in the experiment as part of an introductory course in personality. ${ }^{1}$ Participants' mean age was 22.41 years (range, 1932 years). In the subsample of 56 participants (46 women and 10 men) who completed the Operant Motive Test (OMT, Kuhl \& Scheffer, 1999), participants' mean age was 21.96 years (range, 1931 years; $N=99$, one person did not provide information about her age).

During the first meeting of an introductory course in diagnostics, participants were given the fear of failure and hope-for-success measures (OMT, see below) and were asked to fill it out at home by the following week. At the beginning

${ }^{1}$ Twelve participants were obviously not committed to participating in the study. They were too late for class, showed signs of not concentrating or were disturbed during the administration of the test. These observations were statistically confirmed by suspicious deviations in the performance measures of 10 participants (differences of more than 5 points between the two analogy tasks, which is about 2.5 standard deviations) and missing analogy tasks at T1 and/or T2 from 2 participants. Therefore, these students were not included in the study. 
of the next course meeting, participants were asked to participate in an analogy task from an IQ test. The procedure was the same as in Study 1 with the exception that we additionally assessed participants' avoidance relative to approach motivation directly after the number priming. Thirty-three (18 with OMT) participants were in the failure prime group, 32 (18 with OMT) participants in the success prime group and 35 (20 with OMT) in the control group. In a final short questionnaire, participants answered questions regarding their age, sex, and the purpose of the study ("What do you think we were trying to test in our study?"). At the end of the experiment, participants were asked to hand in both test booklets and the completed OMT. Furthermore, participants answered the same questions regarding their awareness of the numbers and suspicion about the purpose of the test version as in Study 1 .

\section{Materials}

The same performance measure was used as in Study 1 .

\section{Fear of Failure and Hope for Success}

The OMT (Kuhl \& Scheffer, 1999) was administered to assess participants' fear of failure and hope for success. The OMT is a sophisticated measure for assessing implicit motives (achievement, affiliation, and power motive) by presenting participants with 15 pictures and asking them to provide their spontaneous associations to four questions (e.g., What is important for the person in this situation and what is the person doing? How does the person feel?). For the purpose of the present study, participants' answers were scored using the fear-of-failure categories (i.e., "pressure to achieve" and "failure") and the hopefor-success categories (i.e., "flow," "inner standards," and "challenge") of the OMT's scoring system. The interrater agreement between two independent raters was 0.94. Extensive research on the OMT has been reported in Scheffer (2005) and Scheffer, Kuhl, and Eichstaedt (2003) as well as in Baumann, Kaschel, and Kuhl (2005), Baumann, Kazén, and Kuhl (2010), and Kuhl, Scheffer, and Eichstaedt (2003).

\section{Avoidance Motivation}

One item assessed participants' approach orientation ("It was important for me to perform well in the analogy task") and one item avoidance orientation ("I wanted to avoid performing poorly in the analogy task") on a scale from 1 (not at all) to 7 (completely). In line with previous studies on avoidance motivation (Elliot \& Sheldon, 1997; Elliot, Sheldon, \& Church, 1997), a relative avoidance score was calculated, which represents avoidance motivation as a proportion of the overall motivation (avoidance/(approach plus avoidance)).

\section{Results and Discussion}

\section{Descriptives}

Descriptive information and correlations are provided in Table 1. The subsample who filled out the OMT was not significantly different from the full sample in age $(t(96)=1.80$, $p<0.08)$, baseline performance $(t(97)=-1.02, n s)$, or avoidance motivation $(t(97)=0.05, n s)$.

\section{Awareness of Number}

The analysis of the short final questionnaire showed that most participants recalled the test version number correctly. Only five participants did not recall a test version number. Not a single participant guessed that the version number had anything to do with the experiment. All participants were unaware of the purpose of the experiment.

\section{Analogy Task Performance}

In the full sample, an analysis of covariance controlling for performance at $\mathrm{T} 1$ revealed a significant effect of prime type on performance at T2, $F(2,96)=3.94, p<0.03, \varepsilon^{2}=0.08$. Pairwise comparisons adjusted for multiple comparisons (Sidak) revealed that performance of the failure symbol group $(M=11.82, S E=0.31)$ differed significantly from performance of the success symbol group $(M=13.01, S E=0.31)$, (mean difference $=-1.19, S E=0.44, p=0.01,95 \% \mathrm{CI}$ : $\mathrm{LL}-2.06$ to $\mathrm{UL}-0.32)$ and marginally from the control group $(M=12.65$, $S E=0.30$ ) (mean difference $=-0.84, S E=0.43, p=0.06,95 \%$ CI: LL -1.69 to UL 0.19 ). However, the success symbol group and the control group did not differ significantly (mean difference $=0.35, S E=0.44, p=0.43,95 \%$ CI: LL -0.52 to UL 1.23). The results are illustrated in Figure 1(b).

Table 1. Summary of intercorrelations, means, and standard deviations for variables in Study 2 (Full sample of $N=100$ above the diagonal; OMT sample of $N=56$ below the diagonal)

\begin{tabular}{|c|c|c|c|c|c|}
\hline & 1. & 2. & 3. & 4. & 5. \\
\hline \multicolumn{6}{|l|}{ 1. OMT: Fear of failure } \\
\hline 2. OMT: Hope for success & $-0.31 *$ & & & & \\
\hline 3. Performance $\mathrm{T} 1$ & -0.03 & -0.01 & & $0.59 * * *$ & -0.09 \\
\hline 4. Performance T2 & -0.20 & 0.00 & $0.63 * * *$ & & $-0.27 *$ \\
\hline 5. Avoidance motivation & $0.38 * *$ & -0.01 & -0.01 & $-0.32 *$ & \\
\hline$M$ & 1.23 & 1.48 & 12.95 & 12.91 & 0.52 \\
\hline$S D$ & 0.97 & 0.99 & 1.93 & 2.09 & 0.16 \\
\hline Scale range & 015 & 015 & 020 & 020 & 0.130 .88 \\
\hline Observed range & 04 & 03 & 917 & 917 & 0.130 .88 \\
\hline
\end{tabular}

OMT, Operant Motive Test

$* p<0.05 * * p<0.01 * * * p<0.001$ 


\section{Avoidance Motivation}

To test whether motive dispositions moderated the effects of number priming on avoidance motivation, in the OMT subsample, we tested a hierarchical regression analysis with avoidance motivation as the dependent variable. Consistent with Abelson and Prentice (1997), we used C1 (failure number $=2$, success number $=-1$, and control number $=-1$ ) and C2 (failure number $=0$, success number $=-1$, and control number $=1$ ) as planned contrasts for the priming conditions. Contrasts (C1 and $\mathrm{C} 2$ ) and motive dispositions (fear of failure and hope for success) were entered in step 1. Interaction terms were entered in step 2 (see Table 2). Both motive dispositions were mean centered before calculating interaction terms. Results revealed a marginal main effect of $\mathrm{C} 1$ indicating that priming the failure number 6 evoked significantly stronger avoidance motivation compared with priming the success number 1 and the control number $7(\beta=0.03, S E=0.01$, $p=0.06)$. In addition, there was a significant main effect of fear of failure indicating that participants high in fear of failure had significantly higher avoidance motivation than participants low in fear of failure $(\beta=0.05, S E=0.02, p<0.05)$. More important, there was a significant $\mathrm{C} 1 \times$ fear of failure interaction $(\beta=0.03, S E=0.01, p<0.05)$ (Overall model: $\left.\Delta R^{2}=0.37, F(8 / 55)=3.38, p<0.01\right)$. The result is depicted in Figure 3. Consistent with expectations, simple slope

Table 2. Hierarchical regression analyses predicting avoidance motivation from number priming and motive dispositions in Study 2

\begin{tabular}{lccc}
\hline Predictor & $\Delta R^{2}$ & $\beta$ & $t$ \\
\hline Main effects & $0.26^{* *}$ & & \\
C1 (failure prime) & & 0.27 & $2.15^{*}$ \\
C2 (success prime) & & -0.10 & -0.82 \\
Fear of failure (FF) & & 0.39 & $2.97^{* *}$ \\
Hope for success (HS) & & 0.11 & 0.86 \\
Interaction effects & 0.10 & & \\
C1 $\times$ FF & & 0.29 & $2.17^{*}$ \\
C1 $\times$ HS & & 0.16 & 1.23 \\
C2 $\times$ FF & 0.15 & 1.20 \\
C2 $\times$ HS & & 0.05 & 0.37 \\
\hline
\end{tabular}

$* p<0.05 * * p<0.01$

C1 (failure 2, success -1 , and control -1) and C2 (failure 0 , success -1 , and control 1)

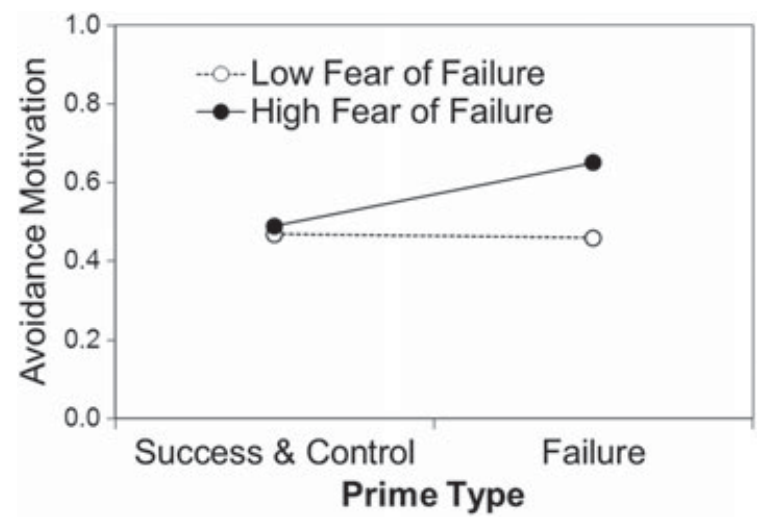

Figure 3. Avoidance motivation as a function of prime type and fear of failure (Study 2) analyses yielded a significant effect of failure priming for participants high in fear of failure, $\beta=0.06, t=3.14, p<0.01$, and no significant effect for participants low in fear of failure, $\beta=-0.01, t=-0.16$, ns.

\section{Direct Effects on Performance}

To test whether motive dispositions moderated the effects of number priming on performance at $\mathrm{T} 2$, in the OMT subsample, we tested a hierarchical regression analysis with performance at $\mathrm{T} 1$ entered in step 1, main effects in step 2, and interaction effects in step 3 (see Table 3 , left columns). There was a significant $\mathrm{C} 1 \times$ fear of failure interaction $(\beta=-0.40, S E=0.15$, $p<0.01$ ), indicating that priming the failure number 6 (compared with success number 1 and control number 7) reduced performance more strongly with higher levels of fear of failure (Overall model: $\left.\Delta R^{2}=0.53, F(9 / 55)=5.84, p<0.001\right)$.

To test whether avoidance motivation had a significant effect on performance at T2, we additionally included avoidance motivation in step 1 (see Table 3, right columns). Consistent with expectations, the regression analysis revealed a significant main effect of avoidance motivation on performance at $\mathrm{T} 2(\beta=-4.14, S E=1.25, p<0.01)$. The $\mathrm{C} 1 \times$ fear of failure interaction was descriptively smaller but significant when controlling for avoidance motivation $(\beta=-0.30, S E=$ $0.15, p<0.05)$. Findings are consistent with the assumption that avoidance motivation partially mediates the effect of number priming on performance and that fear of failure moderates this mediation.

\section{Conditional Indirect Effects on Performance}

To further test whether the indirect effect of failure priming on performance through evoked avoidance motivation was moderated by fear of failure, we tested a moderated mediation model using the PROCESS macro (Model 7) by Hayes (2012, in press). $\mathrm{C} 1$ was entered as a predictor, fear of failure as a moderator, avoidance motivation as a mediator, and performance at T2 (controlling for performance at T1) as an outcome. Consistent with expectations, the mediator variable model revealed a significant $\mathrm{C} 1 \times$ fear of failure interaction on avoidance motivation $(\beta=0.03, S E=0.01, t=2.16$, $p<0.04$ ), and the dependent variable model revealed a significant main effect of avoidance motivation on performance $(\beta=-4.42, S E=1.35, t=-3.27, p<0.002)$. The significance of the indirect effect of failure priming was verified across each level of fear of failure with bootstrapped standard errors and $95 \%$ confidence intervals (CIs). As expected, the indirect effect of failure priming on performance through evoked avoidance motivation was significant among participants with moderate and high levels of fear of failure (because the limits of the $95 \%$ CI did not include zero) but not for participants with low fear of failure (see Table 4).

Moderated mediation analyses with $\mathrm{C} 2$ and/or hope for success revealed no significant $\mathrm{C} \times$ motive interaction effects on avoidance motivation. Furthermore, there were no indirect effects of success priming through evoked avoidance motivation on performance.

In Study 2, we replicated the performance reducing effect of an incidental priming with a failure number. In addition, 
Table 3. Hierarchical Regression Analyses Predicting Performance from Number Priming and Motive Dispositions without (left part of table) or with controlling for avoidance motivation (right part of the table) (Study 2)

\begin{tabular}{|c|c|c|c|c|c|c|}
\hline Predictor & $\Delta R^{2}$ & $\beta$ & $t$ & $\Delta R^{2}$ & $\beta$ & $t$ \\
\hline Control variable(s) & $0.40 * * *$ & & & $0.50 * * *$ & & \\
\hline Performance T1 & & 0.63 & $6.02 * * *$ & & 0.65 & $6.60 * * *$ \\
\hline Avoidance motivation & & & & & -0.32 & $-3.32 * *$ \\
\hline Main effects & 0.04 & & & 0.06 & & \\
\hline $\mathrm{C} 1$ (failure prime) & & -0.02 & -0.20 & & 0.07 & 0.65 \\
\hline $\mathrm{C} 2$ (success prime) & & -0.06 & -0.50 & & -0.10 & -0.93 \\
\hline Fear of failure (FF) & & -0.20 & -1.71 & & -0.07 & -0.59 \\
\hline Hope for success (HS) & & -0.05 & -0.47 & & -0.01 & -0.15 \\
\hline Interaction effects & $0.09^{+}$ & & & 0.06 & & \\
\hline $\mathrm{C} 1 \times \mathrm{FF}$ & & -0.32 & $-2.71 * *$ & & -0.24 & $-2.03 *$ \\
\hline $\mathrm{C} 1 \times \mathrm{HS}$ & & -0.14 & -1.24 & & -0.10 & -0.85 \\
\hline $\mathrm{C} 2 \times \mathrm{FF}$ & & 0.02 & 0.19 & & 0.06 & 0.50 \\
\hline $\mathrm{C} 2 \times \mathrm{HS}$ & & -0.11 & -0.82 & & -0.11 & -0.85 \\
\hline
\end{tabular}

${ }^{+} p<0.10 * p<0.05 * * p<0.01 * * * p<0.001$

$\mathrm{C} 1$ (failure 2, success -1 , control -1 ) $\mathrm{C} 2$ (failure 0 , success -1 , control 1)

Table 4. Conditional indirect effects of failure number priming (C1) on performance through avoidance motivation at different values $(\mathrm{M} \pm 1 \mathrm{SD})$ of fear of failure in Study 2

\begin{tabular}{lrrccc}
\hline & \multicolumn{5}{c}{$\mathrm{DV}=$ Performance T2 } \\
\cline { 2 - 6 } & & \multicolumn{1}{c}{$b$} & $S E$ & Boot $C I$ LL & Boot $C I U L$ \\
\hline Fear of Failure & -1 & 0.00 & 0.08 & -0.13 & 0.19 \\
& 0 & -0.12 & 0.07 & -0.29 & -0.01 \\
& +1 & -0.25 & 0.14 & -0.57 & -0.02 \\
\hline
\end{tabular}

$* p<0.05 * * p<0.01 * * * p<0.001$

Study 2 allowed a more detailed analysis of the mechanism, which underlies the association between failure priming and cognitive performance. A moderated mediation model confirmed the hypothesis that the effect of the failure prime on performance through evoked avoidance motivation does not hold true for everybody but depends on the individuals' achievement motives. More specifically, fear of failure moderated the effect of failure priming (compared with success priming and control group) on evoked avoidance motivation in the expected direction (Figure 3) and was insignificant for success number priming (Table 2). Hope for success did not moderate the effects of number priming.

\section{GENERAL DISCUSSION}

We assumed that arbitrary environmental cues such as numbers can be associated with failure due to a learning history in the educational system and thereby evoke avoidance motivation. This, in turn, was hypothesized to decrease performance in a cognitive task. Furthermore, we tested whether the effect of failure number primes are different for individuals with high versus low levels of achievement motivation. We assumed that the avoidance component of the achievement motive (fear of failure) is a relevant moderator in the assumed mediation and additionally tested the approach component of the achievement motive (hope for success).
Two studies with Swiss and German undergraduate students showed a consistent result pattern for the predictor criterion link of our mediation model by confirming the association between failure priming and cognitive performance. In accordance with our hypotheses, the performance of participants who were exposed to the failure primes was significantly reduced compared with the success prime and the control groups. Study 2 allowed a detailed analysis that revealed the mechanism of this relationship. The failure number priming but not the success number priming evoked avoidance motivation in individuals with moderate and high levels of the achievement motive (fear of failure and hope for success). Avoidance motivation, in turn, impaired performance in a cognitive task.

Two aspects of the results need further discussion. First, that the failure primes had much stronger effects than the success primes is in accordance with the findings of previous research showing either no (Elliot et al., 2007) or weaker effects (Ciani $\&$ Sheldon, 2010) for the priming of success compared with failure. This might be explained by a negativity bias of information processing (Cacioppo \& Berntson, 1994; Cacioppo, Gardner, \& Berntson, 1997, 1999). For example, Cacioppo et al. (1997) suggest that the cognitive system is more responsive to negative than to positive stimuli (see also Baumeister, Bratslavsky, Finkenaur, \& Vohs, 2001), which has meanwhile been confirmed in different domains (loss aversion, e.g., Kahneman \& Tversky, 1984 and electrocortical potentials, e.g., Cacioppo, Crites, \& Gardner, 1996). We assume that a negativity bias also accounted for the difference in the strength of the effects of failure cue versus success cue priming on performance in our research. A second aspect of the results was not hypothesized. The achievement motive components fear of failure and hope of success interacted quite similar with the failure priming (although the effects were stronger for the former than for the latter). Individuals for whom achievement situations are highly relevant seemed to be more sensitive towards cues, which signal the evaluation of their achievement. Due to the negativity bias mentioned earlier, this is especially true for cues signaling failure such as numbers symbolizing bad grades.

Overall, the results indicate the following answers to the open research questions. Besides colors (Elliot et al., 2007) and letters (Ciani \& Sheldon, 2010), also other cues can carry 
the meaning of failure and thereby impair cognitive performance. That arbitrary cues such as numbers easily acquire the capacity to prime avoidance and thus influence performance is a first strong evidence that learning processes rather than ingrained predispositions (as Elliot et al., 2007, 2009 suggested for their "red" prime) link an environmental cue to success and failure. The second evidence is that one and the same cue can carry diametrically opposite meanings depending on the cultural learning history. In the Swiss sample, the number 1 worked well as a failure prime, whereas in the German sample, the number 6 worked as a failure prime because of a different grading system.

Regarding the research question whether individual differences might influence the assumed mediation, it can be said that the effects are indeed stronger for individuals who are dispositionally sensitive towards the evaluation of their performance.

\section{LIMITATIONS AND FUTURE PERSPECTIVES}

Besides the strengths of the present studies, we would also like to note some potential limitations and research questions that still remain open. One limitation is that in the present research, we assumed but did not measure directly that grades are highly personally important (e.g., for one's self-esteem) and therefore easily carry the meaning of personal success and failure, which in turn influence motivation and performance. Whether the strength of the priming effect varies according to the personal importance of grades can only be answered by a future empirical test. Is the priming effect stronger, for example, for individuals whose academic career depends on grades (e.g., undergraduate students) and who define themselves by their academic performance, as compared with individuals who do not necessarily need high grades for their future career (e.g., mature students) and who do not care about grades?

A second major limitation is that we used a two-item measure to assess avoidance motivation. Future research is needed to optimize the avoidance motivation measure and replicate the mediation effect of the present research. An optimization would be to use a broad range of different operationalizations of avoidance motivation, such as questionnaires with more items (Elliot \& McGregor, 2001), implicit measures of avoidance (e.g., word-completion tasks; Ciani \& Sheldon, 2010), behavioral outcomes (preference for easy and difficult rather than for mean task difficulties), and greater right, relative to left frontal cortical activation (Elliot et al., 2007).

In our research, we refer to the avoidance motivation literature and tested avoidance motivation as a mediator in the failure prime impaired performance relationship. However, future research might want to test further potential emotional (e.g., anxiety or dejection) and cognitive (e.g., worry or interfering thoughts) processes, and their potential interplay with motivational processes (e.g., avoidance motivation).

Future research could address the domain-specificity of number primes. Elliot et al. (1997) showed that the color red has different effects in different contexts. Thus, in academic contexts, red symbolizes failure (mistakes marked in red ink) and evokes avoidance motivation, whereas in romantic and sexual relationships (red lipstick for women and red as a signal for male status), the color red is associated with sexual attraction and approach motivation (Elliot et al., 2010). In terms of numbers, it could be tested whether the number 1 in Switzerland has different effects in academic contexts in which it symbolizes failure and in sports contexts, where it symbolizes success (being "the first", the winner's rostrum is marked with the number 1).

\section{CONCLUDING REMARKS}

Failure and success symbols and grades as instruments to evaluate students' performance do not only affect the academic career (which might be the intended effect) but also have some unintended and often unwanted effects. Thus, grades affect feelings of self-worth (Covington, 1992; Covington \& Roberts, 1994) and subsequent motivation, and threaten self-esteem (Butler \& Nisan, 1986). For the sake of students' well-being and performance, a careful and motivation-enhancing use of evaluation systems is absolutely essential. One example is to give self-referenced rather than social-comparative performance feedback (Ames, 1992; Dweck, 1986). A speculation that needs to be tested in future research is whether it is possible to associate a cue for inadequate performance (e.g., bad grade) with a positive meaning (e.g., opportunity to learn and improve one's skills). Hence, even a subtle cue for inadequate performance, such as grade 1 in Switzerland and grade 6 in Germany, would not increase the student's avoidance motivation and would not impair performance.

In concluding, our results advance the understanding of the differential effects and mediating mechanism associated with subtle, learned avoidance cues such as numbers typically used for grading in educational settings.

\section{REFERENCES}

Aarts, H., \& Dijksterhuis, A. (2003). The silence of the library: Environment, situational norm, and social behavior. Journal of Personality and Social Psychology, 84, 18 28. DOI:10.1037/0022 3514.84.1.18

Abelson, R. P., \& Prentice, D. A. (1997). Contrast tests of interaction hypotheses. Psychological Methods, 2, 315 328. DOI:10.1037/1082 989X.2.4.315

Ames, C. (1992). Classrooms: Goals, structures, and student motivation. Journal of Educational Psychology, 84, 261 271. DOI:10.1037/0022 0663.84.3 261

Amthauer, R., Brocke, B., Liepmann, D., \& Beauducel, A. (1999). Intelligenz. struktur test [Intelligence structure test]. Göttingen, Germany: Hogrefe.

Atkinson, J. W. (1957). Motivational determinants of risk taking behaviour. Psychological Review, 64, 359 372. DOI:10.1037/h0043445

Bargh, J. A., \& Chartrand, T. L. (1999). The unbearable automaticity of being. American Psychologist, 54(7), 462 479. DOI:10.1037/0003 066X 54.7.462

Baumann, N., Kaschel, R., \& Kuhl, J. (2005). Striving for unwanted goals: Stress dependent discrepancies between explicit and implicit achievement motives reduce subjective well being and increase psychosomatic symptoms. Journal of Personality and Social Psychology, 89, 781799. DOI:10.1037/0022 3514.89.5.781

Baumann, N., Kazén, M., \& Kuhl, J. (2010). Implicit motives: A look from personality systems interaction theory. In O. C. Schultheiss, \& J. C. Brunstein (Eds.), Implicit motives (pp. 375 403). New York, NY: Oxford University Press. DOI:10.1037/0022 3514.89.5.781

Baumeister, R. F., Bratslavsky, E., Finkenaur, C., \& Vohs, K. (2001). Bad is stronger than good. Review of General Psychology, 5, 323370.

Birney, R. C., Burdick, H., \& Teevan, R. C. (1969). Fear of failure. New York: Van Norstrand Reinhold.

Brunstein, J. C., \& Heckhausen, H. (2008). Achievement motivation. In J. Heckhausen, \& H. Heckhausen (Eds.), Motivation and action (pp. 137 183). Cambridge: Cambridge University Press. DOI:10.1017/ CBO9780511499821.007 
Butler, R., \& Nisan, M. (1986). Effects of no feedback, task related comments, and grades on intrinsic motivation and performance. Journal of Educational Psychology, 78, 210 216. DOI:10.1037/0022 0663.78.3.210

Cacioppo, J. T., \& Berntson, G. G. (1994). Relationship between attitued and evaluative space: A critical review, with emphasis on the separability of positive and negative substrates. Psychological Bulletin, 115, 401423.

Cacioppo, J. T., Crites, S. L., Jr , \& Gardner, W. L. (1996). Attitudes to the right : Evaluative processing is associated with lateralized late positive event related brain potentials. Personality and Social Psychology Bulletin, 22, 12051219.

Cacioppo, J. T., Gardner, W. L., \& Berntson, G. G. (1997). Beyond bipolar conceptualizations and measures: The case of attitudes and evaluative space. Personality and Social Psychology Review, 1, 325.

Cacioppo, J. T., Gardner, W. L., \& Berntson, G. G. (1999). The affect system has parallel and integrative processing components: Form follows function. Journal of Personality and Social Psychology, 76, 839 855. DOI:10.1037/ 0022 3514.76.5.839

Chen, M., \& Bargh, J. A. (1999). Consequences of automatic evaluation: Immediate behavioral predispositions to approach or avoid the stimulus Personality and Social Psychology Bulletin, 25(2), 215 224. DOI:10.1177/ 0146167299025002007

Ciani, K. C., \& Sheldon, K. M. (2010). A versus F: The effects of implicit letter priming on cognitive performance. British Journal of Educational Psychology, 80, 99 119. DOI:10.1348/000709909X466479

Coats, E. J., Janoff Bulman, R., \& Alpert, N. (1996). Approach versus avoidance goals: Differences in self evaluation and well being. Personality and Social Psychology Bulletin, 2, 1057 1067. DOI:10.1177/01461672962210009

Covington, M. V. (1992). Making the grade: A self worth perspective on motivation and school reform. New York: Cambridge University Press.

Covington, M. V., \& Omelich, C. L. (1991). Need achievement revisited: Verification of Atkinson's original $2 \times 2$ model. In C. D. Spielberger, I. G. Sarason, Z. Kulcsar, \& G. L. van Heck (Eds.), Stress and emotion: Axiety, anger, and curiosity (Vol. 14, pp. 85 105). Washington, DC: Hemisphere.

Covington, M. V., \& Roberts, B. W. (1994). Self worth and college achievement: Motivational and personality correlates. In P. R. Pintrich, D. R. Brown, \& C. E. Weinstein (Eds.), Student motivation, cognition, and learning (pp. 157 188). Hillsdale, NJ: Erlbaum.

DeMarree, K. G., Wheeler, S. C., \& Petty, R. E. (2005). Priming a new identity: Effects of non self stereotype primes and self monitoring on the self concept. Journal of Personality and Social Psychology, 90, 666671. DOI:10.1037/0022 3514.89.5.657

Dweck, C. (1986). Motivational processes affecting learning. American Psychologist, 41, 1040 1048. DOI:10.1037/0003 066X.41.10.1040

Elliot, A. J. (2005). A conceptual history of the achievement goal construct. In A. J. Elliot, \& C. S. Dweck (Eds.), Handbook of competence and motivation (pp. 52 72). New York: Guilford Press.

Elliot, A. J. (2008). Approach and avoidance motivation. In A. J. Elliot (Ed.), Handbook of approach and avoidance motivation (pp. 3 14). New York: Psychology Press.

Elliot, A. J., \& Church, M. (1997). A hierarchical model of approach and avoidance achievement motivation. Journal of Personality and Social Psychology, 72, 218 232. DOI:10.1037/0022 3514.72.1.218

Elliot, A. J., \& Friedman, R. (2007). Approach avoidance: A central charac teristic of personal goals. In S. D. Philips, B. R. Little, \& K. Salmela Aro (Eds.), Personal project pursuit: Goals, action, and human flourishing (pp. 97 118). Mahwah, NJ, US: Lawrence Erlbaum Associates Publishers.

Elliot, A. J., \& Maier, M. A. (2007). Color and psychological functioning. Current Directions in Psychological Science, 16, 250 254. DOI:10.1111/ j.1467 8721.2007.00514.x

Elliot, A. J., Maier, M. A., Binser, M. J., Friedman, R., \& Pekrun, R. (2009). The effect of red on avoidance behavior in achievement contexts. Personality and Social Psychology Bulletin, 3 (3), 365 375. DOI:10.1177/0146167208328330
Elliot, A. J., Maier, M. A., Moller, A. C., Friedman, R., \& Meinhardt, J. (2007). Color and psychological functioning: The effects of red on perfor mance attainment. Journal of Experimental Psychology. General, 136, 154 168. DOI: $10.1037 / 00963445.136 .1 .154$

Elliot, A. J., \& McGregor, H. A. (1999). Test anxiety and the hierarchical model of approach and avoidance achievement motivation. Journal of Personality and Social Psychology, 76, 628 644. DOI:10.1037/0022 3514.76.4.628

Elliot, A. J., \& McGregor, H. A. (2001). A $2 \times 2$ achievement goal framework. Journal of Personality and Social Psychology, 80, 501 515. DOI:10.1037/ 0022 3514.80.3.501

Elliot, A. J., Niesta Kayser, D., Greitemeyer, T., Lichtenfeld, S., Gramzow, R. H., \& Maier, M. A. (2010). Red, rank and romance in women viewing men. Journal of Experimental Psychology, 139, 3, 399417.

Elliot, A. J., \& Sheldon, K. M. (1997). Avoidance achievement motivation: A personal goals analysis. Journal of Personality and Social Psychology, 73, 171 185. DOI:10.1037/0022 3514.73.1.171

Elliot, A. J., Sheldon, K. M., \& Church, M. A. (1997). Avoidance personal goals and subjective well being. Personality and Social Psychology Bulletin, 23(9), 915927.

Elliot, A. J., \& Thrash, T. M. (2001). Achievement goals and the hierarchical model of achievement motivation. Educational Psychology Review, 12, 139 156. DOI:10.1023/A:1009057102306

Hayes, A. F. (2012). PROCESS: A versatile computational tool for observed variable mediation, moderation, and conditional process modeling [White paper]. Retrieved from http://www.afhayes. com/public/process2012.pdf

Hayes, A. F. (in press). An introduction to mediation, moderation, and conditional process analysis: A regression based approach. New York: Guilford Press.

Kahneman, D., \& Tversky, A. (1984). Choices, values, and frames. American Psychologist, 39, 341350.

Kuhl, J., \& Scheffer, D. (1999). Der operante Multi Motiv Test (OMT): Manual [Scoring Manual for the Operant Multimotive Test (OMT)]. Osnabrück, Germany: University of Osnabrück.

Kuhl, J., Scheffer, D., \& Eichstaedt, J. (2003). Der Operante Motiv Test (OMT): Ein neuer Ansatz zur Messung impliziter Motive [The operant Mo tive Test (OMT): A new approach to the assessment of implicit motives]. In F. Rheinberg, \& J. Stiensmeier Pelster (Eds.), Diagnostik von Motivation und Selbstkonzept (pp. 129 149). Göttingen, Germany: Hogrefe.

Maier, M. A., Elliot, A. J., \& Lichtenfeld, S. (2008). Mediation of the negative effect of red on intellectual performance. Personality and Social Psychology Bulletin, 34(11), 1530 1540. DOI:10.1177/0146167208323104

McClelland, D. C. (1985). Human motivation. Glenview, IL: Scott, Foresman.

McClelland, D. C., Atkinson, J. W., Clark, R. A., \& Lowell, E. L. (1953). The achievement motive. New York: Appleton Century Crofts. DOI:10.1037/ 11144000.

Moller, A. C., Elliot, A. J., \& Maier, M. A. (2009). Basic hue meaning associations. Emotion, 9(6), 898902.

Puca, R. M., Rinkenauer, G., \& Breidenstein, C. (2006). Individual differences in approach and avoidance movements: How the avoidance motive influences response force. Journal of Personality, 74, 9791014. DOI:10.1111/j.1467 6494.2006.00400.x

Scheffer, D. (2005). Implizite Motive [Implicit motives]. Göttingen, Germany: Hogrefe.

Scheffer, D., Kuhl, J., \& Eichstaedt, J. (2003). Der Operante Motiv Test (OMT): Inhaltsklassen, auswertung, psychometrische kennwerte und validierung [the Operant Motive Test (OMT): Contents, scoring, psycho metric values, and validation]. In J. Stiensmeier Pelster, \& F. Rheinberg (Eds.), Diagnostik von Motivation und Selbstkonzept (pp. 151 167). Göttingen: Hogrefe. 